\title{
INTRODUKSI TEKNOLOGI SABUN CAIR ANTISEPTIK DARI BUAH PEDADA (Sonneratia caseolaris) DI KELURAHAN KAMPUNG LAUT, KUALA JAMBI, TANJUNG JABUNG TIMUR
}

\author{
Faizar Farid ${ }^{1}$, Uce Lestari ${ }^{2}$, Putri Maya Sari ${ }^{3}$, Havizur Rahman ${ }^{4}$ \\ 1,2,3,4 Program Studi Farmasi Fakultas Sains dan Teknologi Universitas Jambi \\ email: ;faizarfarid@unja.ac.id; ucelestari@unja.ac.id; putrimayasari@gmail.com; \\ havizurrahman@yahoo.co.id
}

\begin{abstract}
ABSTRAK.
Buah pedada yaitu buah mangrove yang hidup di perairan payau yang banyak tumbuh di daerah pesisir khususnya yang ada di Kabupaten Tanjab Timur yaitu Kelurahan Kampung Laut Kecamatan Kuala Jambi. Buah Pedada bagian dasarnya dibungkus oleh kelopak bunga, dan tidak beracun. Masyarakat Kampung Laut jarang mengkonsumsi langsung buah Pedada karena rasanya asam. Buah tersebut memiliki kandungan gizi yang belum dimanfaatkan. Buah Pedada dapat diolah menjadi produk pangan seperti selai dan sirup, karena kandungan vitamin $C$ yang cukup tinggi. Selain pengolahan produk pangan buah Pedada dapat juga diolah menjadi sabun cair antiseptik, karena kandungan zat kimia pada buah Pedada mampu membunuh dan menghambat pertumbuhan bakteri. Dengan melihat potensi ini, maka muncul ide untuk membuat teknologi pengolahan sabun cair buah Pedada sebagai antiseptik. Tujuan kegiatan pengabdian kepada masyarakat ini akan memberikan nilai tambah yang besar ditinjau dari hasil teknologi produk sabun cair antiseptik, sehingga menambah nilai ekonomis dan penghasilan bagi Masyarakat Kampung Laut serta meningkatkan pengetahuan masyarakatnya. Metode yang digunakan dalam kegiatan ini penyuluhan manfaat dan pengolahan buah Pedada. Kegiatan ini menghasilkan produk sabun cair antiseptik serta meningkatkan kreativitas sumber daya manusia di Kelurahan Kampung Laut, kecamatan Kuala Jambi, Kabupaten Tanjab Timur untuk membuat industri rumah tangga produk pangan ataupun produk sabun cair antiseptik.
\end{abstract}

\section{Kata Kunci : Buah Pedada, Sabun Cair, Antiseptik, Kampung Laut}

\section{PENDAHULUAN}

Kabupaten Tanjab Timur rnemiliki 11 kecamatan yang sebagiannya berada pada wilayah pesisir yang strategis, dimana pada daerah pesisir tersebut banyak ditemukan Hutan bakau atau hutan mangrove. Hutan mangrove adalah hutan yang tumbuh di atas perairan payau salah satunya berada pada Kelurahan Kampung Laut, Kecamatan Kuala Jambi. Tanaman yang banyak tumbuh pada hutan magrove antara lain tanaman Pedada (Sonneratia caseolaris ).

Buah Pedada rasanya asam, tidak beracun, memiliki kandungan gizi dan vitamin $\mathrm{C}$ yang tinggi dimana buah tersebut belum termanfaatkan sampai saat ini oleh masyarakat. Masyarakat disana belum mendapat informasi cara pengolahan buah pedada menjadi nilai jual yang ekonomis. Buah Pedada dapat diolah menjadi sabun cair antiseptik, karena kandungan zat kimia pada buah Pedada mampu membunuh dan menghambat pertumbuhan bakteri. Selain itu buah pedada dapat diolah dan dijadikan produk pangan seperti sirup, dodol, lempok, juice, minuman instan, permen, tepung untuk pembuatan kue dan lain-lain. 
Teknologi pengolahan sabun cair buah Pedada sebagai antiseptik akan memberikan nilai tambah yang besar ditinjau dari hasil teknologi produk sabun cair antiseptik, sehingga menambah nilai ekonomis dan penghasilan bagi Masyarakat Kampung Laut.

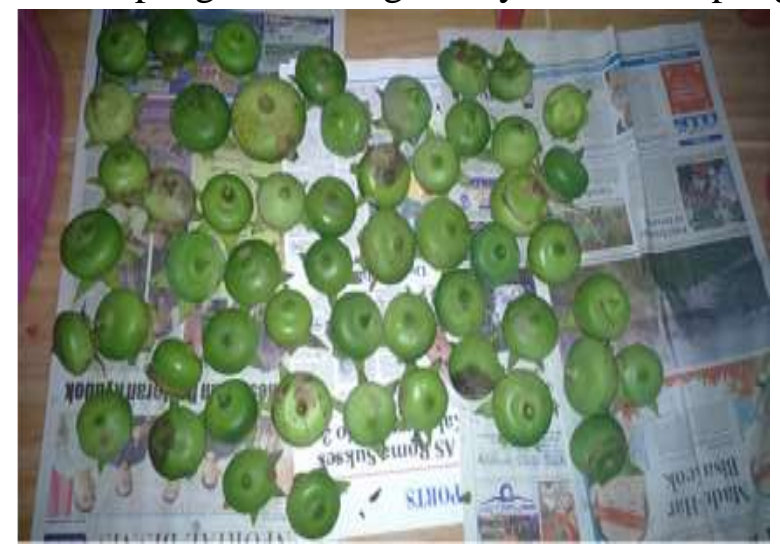

Gambar 1. Buah pedada

Tujuan kegiatan pengabdian kepada masyarakat ini akan memberikan nilai tambah yang besar ditinjau dari penggunaan dan nilai ekonomisnya salah satu nya sebagai sabun cair antiseptik serta meningkatkan pengetahuan masyarakat mengenai manfaat buah pedada sebagai produk kosmetik dan produk pangan yang belum termanfaatkan sampai saat ini.

Dengan melihat potensi ini, maka muncul ide untuk membuat teknologi pengolahan sabun cair antiseptik dari buah pedada dalam hal pemanfaatan buah pedada yang rasanya asam menjadi produk kosmetik dan produk pangan yang memiliki nilai jual yang ekonomis dalam bentuk Aplikasi dan Sosialisasi pemanfaatan buah pedada sebagai sabun cair antiseptik dan inovasi terbaru produk pangan buah pedada kepada ibu-ibu PKK kelurahan Kampung Laut, Kecamatan Kuala Jambi Tanjab Timur.

\section{METODE PELAKSANAAN}

\section{Waktu dan tempat}

Pembuatan sabun cair antiseptik secara tradisional dan secara kimia dibuat pada laboratorium Agroindustri dan tanaman Obat Fakultas Sains dan Teknologi, Universitas Jambi. Penyuluhan atau sosialisasi pemanfaatan buah pedada sebagai sabun cair antiseptik dan inovasi terbaru produk pangan buah pedada yang dilaksanakan pada tanggal 8 September 2017 di Kelurahan Kampung Laut.

\section{Alat dan Bahan}

Sabun cair antiseptik buah pedada, wadah, plastik

\section{Prosedur kerja}

Berikut adalah program kerja yang dilaksanakan dalam kegiatan pengabdian kepada masyarakat ini: 1). Pengolahan buah pedada menjadi sabun cair antiseptik secara tradisional dan secara kimia 2). Sosialisasi pemanfaatan buah pedada sebagai sabun cair antiseptik dan inovasi terbaru produk pangan buah pedada 3) Aplikasi sabun cair buah pedada sebagai sabun cuci tangan antiseptik setelah melakukan kegiatan. 


\section{Pengolahan sabun cair buah pedada sebagai antiseptik}

Pengolahan pasta sabun cair

Tabel 1. Formula Pasta Sabun Cair

\begin{tabular}{crcl}
\hline No & Nama Bahan & Jumlah & \multicolumn{1}{c}{ Keterangan } \\
\hline 1 & Buah pedada & 300 gram & $\begin{array}{l}\text { Buah yang tua direbus dan } \\
\text { dihaluskan }\end{array}$ \\
2 & Lidah buaya & 300 gram & $\begin{array}{l}\text { Direbus dan ambil daging buah } \\
\text { kemudian dihaluskan }\end{array}$ \\
3 & Ragi Tape & 8 butir & - \\
\hline
\end{tabular}

Pembuatan pasta

Ambil daging buah pedada dan dibuang bijinya masukkan dalam wadah. Lalu ambil daging buah lidah buaya masukkan dalam wadah. Rebus buah pedada dan lidah buaya hingga matang semua, kemudian tambahkan Ragi Tape dan dihaluskan semua bahan didalam blender, setelah semua bahan dihaluskan lalu disimpan didalam plastik putih. Kemudian dibungkus didalam plastik hitam disimpan selama 3 hari. Hindarkan dari sinar matahari. Setelah 3 hari bungkusan plastik dibuka, jika sudah menjadi pasta dan tidak berbau proses fermentasi telah berhasil, jika masih berbau ulangi proses tersebut diatas.

\section{Pengolahan Sabun Cair Antiseptik Secara Tradisional.}

Tabel 2. Formula Sabun Cair Dengan Bahan Alami

\begin{tabular}{clc}
\hline No. & \multicolumn{1}{c}{ Nama Bahan } & Jumlah \\
\hline 1 & Pasta sabun cair & 300 gram \\
2 & Garam beryodium & 250 gram \\
3 & Air jeruk nipis & $10 \mathrm{cc}$ \\
4 & Air matang & 4,5 liter \\
\hline
\end{tabular}

Pembuatan sabun cair

Campurkan pasta dan garam lalu dimasukkan air sedikit demi sedikit sambil diaduk. Masukkan air jeruk nipis dan air daun suji aduk rata lalu disaring dan biarkan selama 12 jam sampai terjadi endapan. Kemudian diambil bagian diatasnya jika sabun yang dihasilkan menjadi jernih atau tidak berwarna, maka tambahkan air perasan daun suji sampai memberikan warna hijau yang stabil. 


$\begin{aligned} & \text { Pengolahan Sabun Cair Antiseptik Secara Kimiawi } \\
& \text { Tabel }\end{aligned}$ 3. Formula Sabun Cair Dengan Bahan Kimia
\begin{tabular}{llc}
\multicolumn{1}{c}{ Nama Bahan } & \multicolumn{1}{c}{ Jumlah } \\
\hline 1 & Ekstrak pedada & $5 \%$ \\
2 & Minyak zaitun & $15 \mathrm{ml}$ \\
3 & KOH 40 \% & $8 \mathrm{ml}$ \\
4 & Na CMC & $0,5 \mathrm{gr}$ \\
5 & SLS & $0,5 \mathrm{gr}$ \\
6 & Asam stearat & $0,25 \mathrm{gr}$ \\
7 & BHA & $0,5 \mathrm{gr}$ \\
8 & Pewangi & $1 \mathrm{ml}$ \\
9 & Aquadest & Ad $50 \mathrm{ml}$ \\
\hline
\end{tabular}

\section{Pembuatan sabun cair}

Minyak zaitun sebanyak $15 \mathrm{ml}$ dimasukkan kedalam beaker glass tambahkan $\mathrm{KOH} 40 \%$ sebanyak $8 \mathrm{ml}$ sedikit demi sedikit kemudian dipanaskan pada suhu 50 derajat celcius sampai terbentuknya sabun pasta. Kemudian sabun pasta tambahkan $15 \mathrm{ml}$ aquadest lalu tambahkan NaCMC yang telah dikembangkan kedalam aquadest panas aduk sampai homogen kemudian tambahkan asam stearat tambahkan SLS tambahkan BHA dan tambahkan ekstrak aduk homogen lalu tambahkan aquadest sampai dengan $50 \mathrm{ml}$, sediaan dikemas.

\section{HASIL YANG DICAPAI}

Hasil yang dicapai dalam kegiatan pengabdian kepada masyarakat ini adalah terlaksananya penyuluhan tentang pemanfaatan buah pedada sebagai sabun cair antiseptik dan inovasi terbaru produk pangan buah pedada yang memberikan pengetahuan dan skill bagi ibu-ibu PKK Kelurahan Kampung Laut tentang manfaat buah pedada yang mempunyai nilai ekonomi yang tinggi.

Kegiatan ini telah diawali dengan melakukan koordinasi dengan Lurah Kampung Laut tentang pelaksanaan PPM dengan judul "Indroduksi Teknologi Sabun Cair antiseptik dari Buah Pedada (Sonneratia caseolaris) di Kelurahan Kampung Laut, Kuala Jambi, Tanjab Timur" kepada ibu-ibu PKK Kelurahan Kampung Laut. Hasil koordinasi dengan Lurah Kampung adalah mereka bersedia menjadi mitra dalam pelaksanaan kegiatan PPM ini dengan memberikan surat pernyataan mitra.

Sasaran dari koordinasi ini adalah ibu-ibu PKK Kampung Laut dengan tujuan agar mereka ikut berpartisipasi dalam kegiatan PPM dan mendapatkan hasil pentingnya kegiatan PPM ini dalam memanfaatkan buah pedada yang banyak terdapat di daerah mereka dengan menggunakan teknologi sabun cair baik secara pembuatan tradisional atau menggunakan zat kimia, dimana digunakan sebagai antiseptik atau membunuh kuman/bakteri pada tangan, sehingga memiliki nilai ekonomi yang tinggi.

\section{Pengambilan Buah Pedada Dan Pembuatan Pasta Sabun}

Buah Pedada yang masak diambil sebanyak $10 \mathrm{~kg}$ didaerah Pesisir Kampung Laut, dibersihkan kemudian dicuci dengan air mengalir lalu dikering anginkan didalam ruangan. 
Buah pedada sangat mudah sekali membusuk dikarenakan buah pedada banyak mengandung vitamin $\mathrm{C}$ yang sangat tinggi sehingga mudah teroksidasi. Terbentuknya pasta sabun sangat dipengaruhi oleh buah pedada. Buah pedada ditambah lidah buaya dan dihaluskan dengan ragi tape lalu disimpan selama 3 hari, jika setelah 3 hari penyimpanan atau fermentasi bahanbahan pasta sabun yang disimpan terlindung dari cahaya matahari dihasilkan pasta yang tidak berbau berarti proses fermentasi telah berhasil, jika masih berbau ulangi proses fermentasi tersebut sampai diperoleh pasta sabun putih dan tidak berbau.

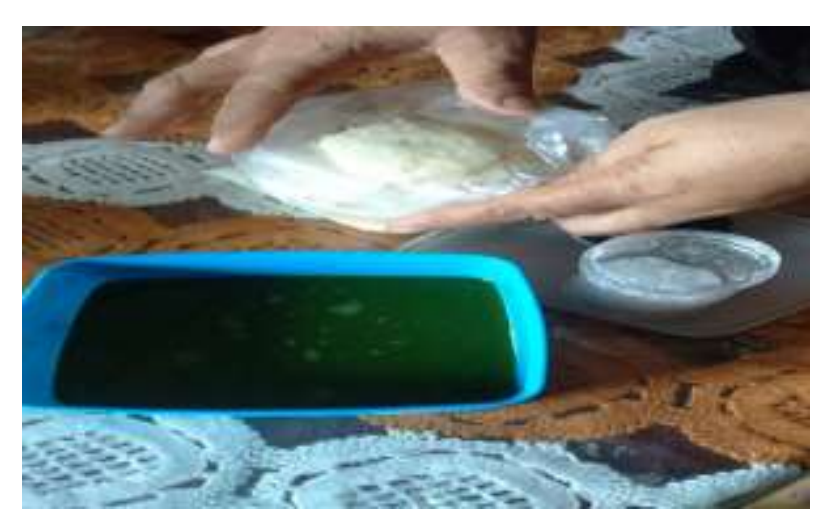

Gambar 2. Pasta Sabun Cair

\section{Pengolahan Sabun Cair Antiseptik Buah Pedada Secara Tradisional}

Campurkan pasta yang telah jadi tadi dengan garam lalu dimasukkan air sedikit demi sedikit sambil diaduk. Masukkan air jeruk nipis dan air daun suji aduk rata lalu disaring dan biarkan selama 12 jam sampai terjadi endapan. Kemudian diambil bagian diatasnya jika sabun yang dihasilkan menjadi jernih atau tidak berwarna, maka tambahkan air perasan daun suji sampai memberikan warna hijau yang stabil. Pembuatan sabun ini harus hati-hati sampai terbentuk busa sabun, jika tidak terbentuk busa berarti proses gagal.

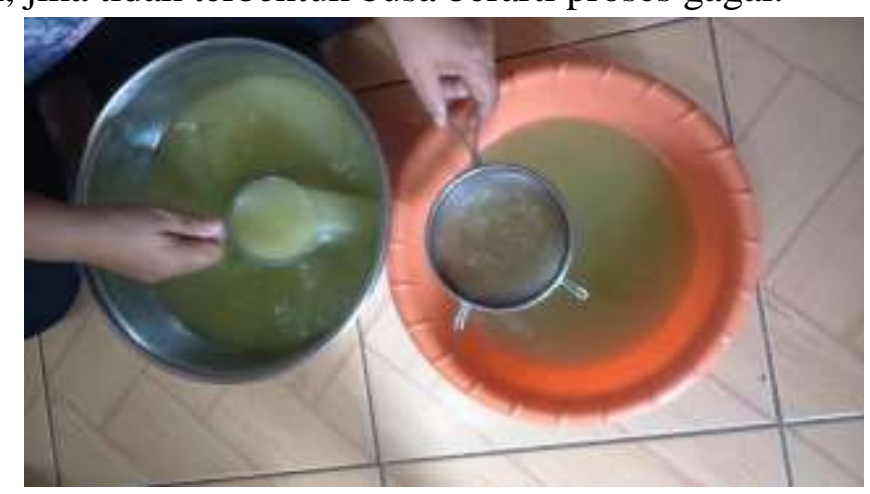

Gambar 3. Sabun Cair Dari Bahan Alami

\section{Pengolahan Sabun Cair Secara Kimiawi}

Minyak zaitun ditambahkan $\mathrm{KOH} 40 \%$ kemudian dipanaskan pada suhu 50 derajat celcius sampai terbentuknya sabun pasta. Kemudian sabun pasta tambahkan aquadest lalu tambahkan NaCMC yang telah dikembangkan kedalam aquadest panas aduk sampai homogen kemudian tambahkan asam stearat tambahkan SLS tambahkan BHA dan tambahkan ekstrak buah pedada aduk homogen lalu tambahkan aquadest sampai dengan $50 \mathrm{ml}$, sediaan dikemas. Sabun cair yang menggunakan bahan kimia diperoleh sabun dengan $\mathrm{pH}$ sangat basa yaitu 12, 
sehingga belum bisa digunakan dan masih dalam proses tahap penelitian selanjutnya agar memperoleh produk sabun cair antiseptik yang stabil dan aman pada penggunaannya.

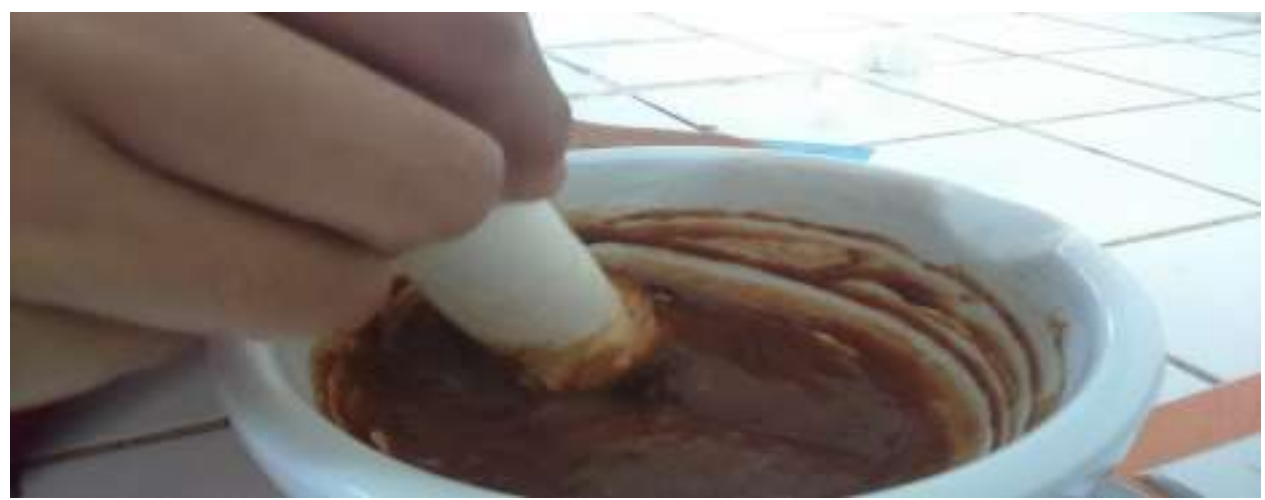

Gambar 4. Sabun Cair Dari Bahan kimia

\section{Sosialisasi Sabun Cair Buah Pedada Sebagai Antiseptik}

Adapun sasaran dari sosialisasi sabun cair buah pedada sebagai antiseptik yang berupa penyuluhan adalah ibu-ibu PKK Kelurahan Kampung Laut yang ikut berpartisipasi dalam pelaksanaan kegiatan ini berjumlah 30 orang.
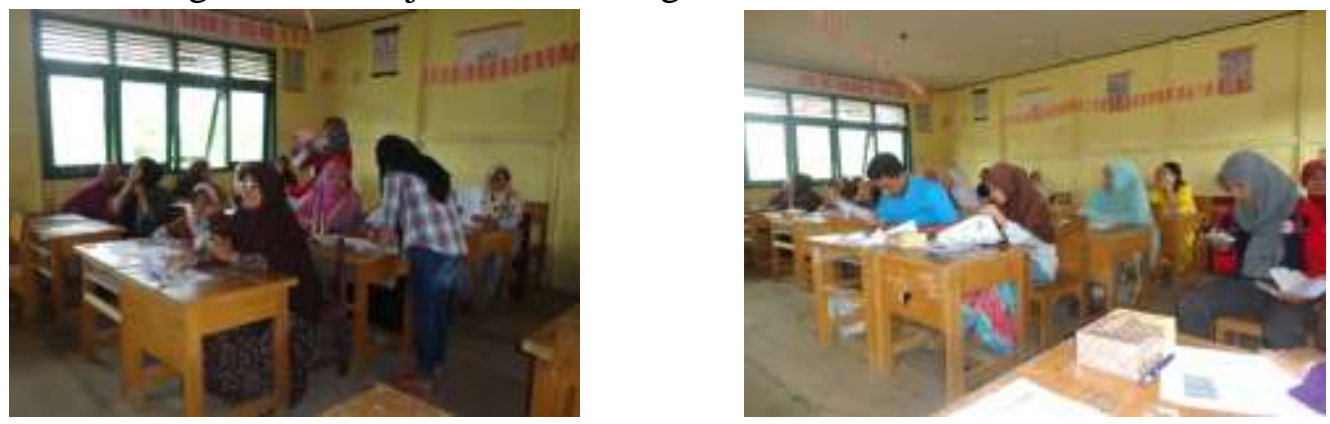

Gambar 5. Peserta Sosialisasi

Ibu -ibu PKK sangat antusias dan aktif dalam mengikuti kegiatan ini dengan banyak memberikan pertanyaan terkait dari pemanfaatan buah pedada menjadi inovasi baru sebagai produk kosmetik dan produk pangan yang dapat memberikan nilai ekonomi yang tinggi.

Dari hasil sosialisasi ini memberikan manfaat yang baik bagi ibu-ibu PKK Kelurahan Kampung Laut dimana mereka mendapatkan wawasan dan ilmu pengetahuan tentang teknologi produk kosmetik sabun cair sebagai antiseptik serta manfaat buah pedada sebagai inovasi baru produk pangan seperti sirup, selai, dodol, lempok, permen, juice, minuman instan, wajik, tepung untuk pembuatan kue dan lain-lain.

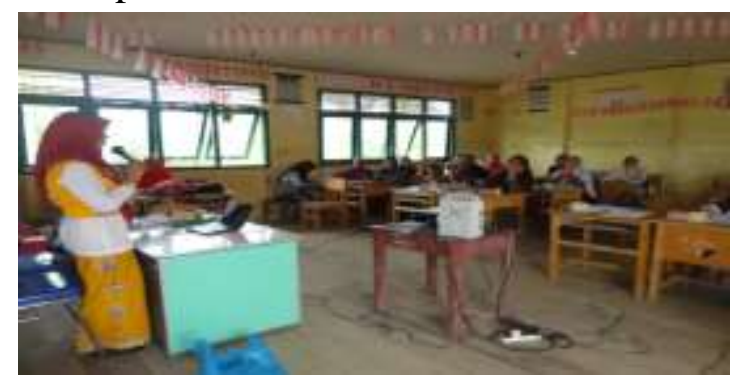

Gambar 6. Penyuluhan Tentang Teknologi Sabun Cair Antiseptik 
Ibu-ibu PKK Kelurahan Kampung Laut sangat senang dan ingin menerapkan atau mengaplikasikan teknologi tepat guna dari buah pedada sebagai sabun cair antiseptik serta mengolah buah pedada sebagai produk olahan makanan dan minuman seperti sirup, dodol, lempok, jus, minuman instan, tepung dalam kehidupan sehari-hari dan harapan nantinya dapat membuat industri rumah tangga yang memiliki nama paten tersendiri.

Setelah penyuluhan tentang introduksi teknologi sabun cair dari buah pedada sebagai antiseptik dilanjutkan pemberian sovenir produk sabun cair antiseptik secara gratis kepada seluruh peserta sosialisasi, dimana terlebih dahulu diawali pemberian secara simbolis kepada ibu Ketua PKK Kelurahan Kampung Laut.

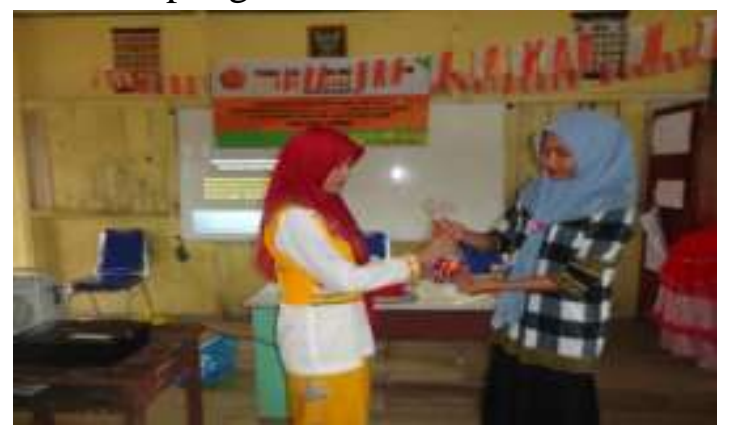

Gambar 7. Pemberian produk sabun cair secara simbolis

Setelah pemberian secara simbolis dilanjutkan pemberian secara gratis kepada ibu-ibu peserta sosialisasi dan dilanjutkan foto bersama dan acara ditutup dengan pembacaan doa.
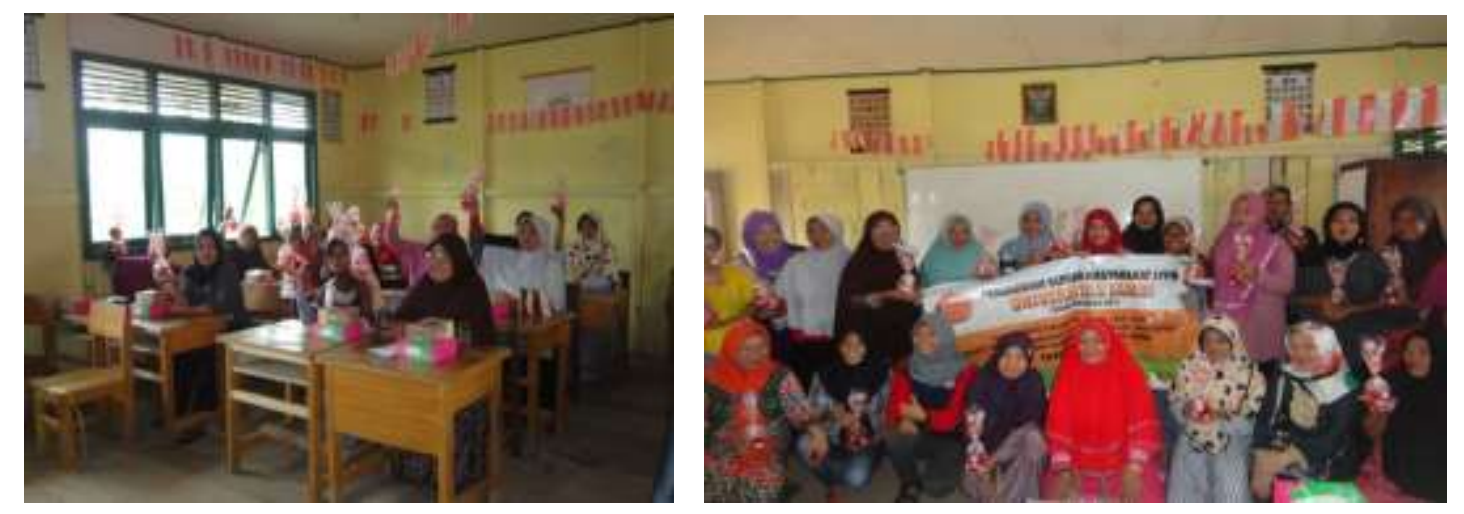

Gambar 8. Pemberian produk sabun cair dan foto bersama

Aplikasi dari teknologi sabun cair sebagai antiseptik dan pemanfaatan buah pedada sebagai inovasi terbaru produk olahan makanan dan minuman akan diterapkan oleh kegiatan ibu PKK Kelurahan Kampung Laut yaitu pada acara perlombaan PKK se kecamatan Kabupaten Tanjab timur yang insha allah akan dilaksanakan pada bulan Desember, dimana sebelum pelaksanaan kegiatan perlombaan tersebut, ibu ketua PKK kelurahan Kampung Laut akan mengundang kembali tim pengabdian pada masyarakat Universitas Jambi untuk melakukan demonstrasi pembuahan produk sabun cair dan produk olahan makanan dan minuman dari buah pedada seperti sirup, dodol, jus, tepung, lempok, minuman instan dan lain-lain. 


\section{KESIMPULAN}

Hasil dari kegiatan sosialisasi tentang teknologi sabun cair antiseptik serta manfaat buah pedada sebagai inovasi baru produk pangan dapat disimpulkan bahwa kegiatan ini memberikan pengetahuan lebih tentang manfaat buah pedada yang mempunyai nilai ekonomis yang tinggi, menghasilkan produk kosmetik sabun cair antiseptik dan produk pangan serta meningkatkan kreativitas sumber daya manusia di sekitar Kelurahan Kampung Laut, Kecamatan Kuala Jambi, Tanjab Timur.

\section{UCAPAN TERIMAKASIH}

Terima kasih untuk pihak yang telah membantu terutama pihak Lurah dan PKK Kelurahan Kampung Laut, Kecamatan Kuala Jambi, Tanjab Timur.

\section{DAFTAR PUSTAKA}

Ansel, H.C. (1989). Pengantar Bentuk sediaan farmasi. (Edisi 4). Jakarta: UI Press.

Anonim. (1995). Farmakope Indonesia. (Edisi IV). Jakarta: Departemen Kesehatan Republik Indonesia.

Alderborn B, 2002, Tablet and Compaction, in Pharmaceutics: The Science of Dosage Form Design, Aulton M.E (Editor), 2nd edition,, Harcourt Publisher, London.

Bokshi, Bishwajit. Zilani, Md Nazmul Hasan. Malakar, Aparajita. Debendra, Nath. Sadhu, Samir Kumar. (2013). Study Of Analgesic And Antidiarrhoeal Activities Of Sonneratia Caseolaris (Linn.) Leaf And Stem Using Different Solvent System. Indonesian J. Pharm, 24, 4, $253-258$

Davies, P, 2001, Oral Solid Dosage Form, in Pharmaceutical Preformulation and Formulation, Gibson M (editor), CRC Press

Jariyah. Widjanarko, Simon B. Yunianta. Estiasih, T. (2015).Phytochemical and Acute Toxicity Studies of Ethanol Extract from Pedada (Sonneratia caseolaris) Fruit Flour (PFF). International Jurnal Advanced Science Engeneering Information Technology,5, 2, 95-98.

Putri, Vinny Sukma Wijayana. Yulita, Victoria. Rijai, Laode. (2015). Aktivitas Antioksidan Kulit Buah Pidada Merah (Sonneratia caseolaris L.). Jurnal Sains dan Kesehatan, 1, 2, 69-74.

Rowe R.C., Sheskey P.J., and Owen., 2006, Handbook of Pharmaceutical Excipients,5th Edition, Pharmaceutical Press, London

Voight, R, 1994. Buku Pelajaran Teknologi Farmasi, Yogyakarta, Gadjah Mada University Press 